\title{
summary
}

\section{Treatment time alone is insufficient to assess societal cost of dental trauma}

Glendor U, Halling A, Bodin L, Andersson L, Nygren A, Karlsson G, Koucheki B. Direct and indirect time spent on care of dental trauma: a 2-year prospective study of children and adolescents. Endod Dent Traumatol 2000; 16:16-23

Objective To account for the total time spent by professional caregivers (direct time) and by patients and companions as support and help (indirect time) to treat and otherwise attend to children and adolescents with dental trauma

Design Cohort Study using a random sample of patients suffering dental trauma during period July 1992 to March 1993.

Intervention The following information was recorded: sex, age, place of residence and injury, date and time of injury, diagnoses, injury mechanism and description of treatment. Patients were followed prospectively for 2 years direct and indirect time spent in connection with treatment was recorded. Patients and/or parents were interviewed on average four times, using a structured question list. Random samples of the notes were tested for validation.

Outcome measures A wide range of outcome measures were assessed, e.g. transport time, waiting time, treatment time, nursing time in hospital and home, other time and total time by geographic, demographic and dental injury parameters.

Results Complicated trauma had a major impact on all time variables; $6 \%$ of primary tooth trauma and $19 \%$ of permanent tooth trauma sought attention outside working hours, with $38 \%$ occurring in

\begin{tabular}{|c|c|c|c|c|}
\hline & \multicolumn{2}{|c|}{ Primary teeth } & \multicolumn{2}{|c|}{ Permanent teeth } \\
\hline & $\begin{array}{l}\text { Uncom- } \\
\text { plicated }\end{array}$ & Complicated & $\begin{array}{l}\text { Uncom- } \\
\text { plicated }\end{array}$ & Complicated \\
\hline $\begin{array}{l}\text { Mean no of visits } \\
\text { (range) }\end{array}$ & $\begin{array}{c}2.0 \\
(1-5)\end{array}$ & $\begin{array}{c}2.8 \\
(1-9)\end{array}$ & $\begin{array}{c}4.1 \\
(1-27)\end{array}$ & $\begin{array}{c}8.9 \\
(1-26)\end{array}$ \\
\hline $\begin{array}{l}\text { Direct time as \% } \\
\text { of total time }\end{array}$ & \multicolumn{2}{|c|}{$11 \%$} & \multicolumn{2}{|c|}{$16 \%$} \\
\hline $\begin{array}{l}\text { Direct time mean } \\
\text { (range) }\end{array}$ & \multirow{2}{*}{\multicolumn{2}{|c|}{$\begin{array}{c}0.8 \mathrm{hrs} \\
(0.1-3.7 \mathrm{hrs}) \\
36 \%\end{array}$}} & \multirow{2}{*}{\multicolumn{2}{|c|}{$\begin{array}{c}2.6 \mathrm{hrs} \\
(0.2-15.8 \mathrm{hrs}) \\
30 \%\end{array}$}} \\
\hline $\begin{array}{l}\text { Transport time } \\
\text { as \% of total time }\end{array}$ & & & & \\
\hline
\end{tabular}

day-care or school environment. Transport time was the largest element of indirect time.

Conclusion This study shows that direct time alone is an insufficient measure of resources spent on dental trauma and that parameters such as degree of severity, place of injury and access to treatment are of major importance with respect to total time spent.

Supported by FOLKSAM Insurance Company and Ostergotland County Council Address for reprints: Ulf Glendor, Unit of Community Dentistry, Centre for Public Heath Services SE-581 85 Linkoping. Sweden.

E-mail: ulf.glendor@telia.com

\section{Commentary}

A significant number of people suffer dental trauma. This article examines the costs, in terms of time spent accessing and receiving care, to dental trauma patients and their carers. The methods used are in general valid and appropriate, although it would have been better to gather the data contemporaneously rather than using a retrospective interview technique.

The study reports data over a 2 -year period; however, the consequences of trauma are in some cases lifelong, and therefore a longer follow-up would have been advantageous. An alternative approach would have used economic modelling to take into account long-term morbidity.

The time implications of trauma reported were considerable to both patient and carer; however, an examination of the opportunity costs would have demonstrated the true implications, for example, lost education and lost time at work, respectively.

As would be anticipated patients with complicated trauma (involving the pulp or periodontal membrane defined in a previous article ${ }^{1}$ ) had a greater treatment need than uncomplicated trauma (without pulp or periodontal membrane injury). If the sample size had permitted, it would have been interesting to investigate the costs of other forms of trauma i.e. intrusion.

This article makes a valuable contribution to the dental trauma literature, it identifies the considerable implications of trauma. The findings indicate the need for access to appropriately trained care and the need for this to be available out of work hours.

The opportunity also has to be taken to note that some dental trauma is avoid- able, for example sporting organisations should encourage the use of mouth guards. The public and health professional should be aware of 'first aid' techniques, as these have significant influence on prognosis. It is also paramount that the dental profession is aware of the evidence indicating best practice.

In conclusion, this paper draws our attention to the significant implications of dental trauma to patient and carer. This is an area in which further studies are warranted.

1. Glendor U, Halling A, Andersson L, EilertPetersson E. Incidence of traumatic tooth injuries in children and adolescents in the county of Västmanland, Sweden. Swed Dent J 1996; 20:15-28.

Chris Deery Dental Health Services Research Unit, University of Dundee, Scotland, UK 